
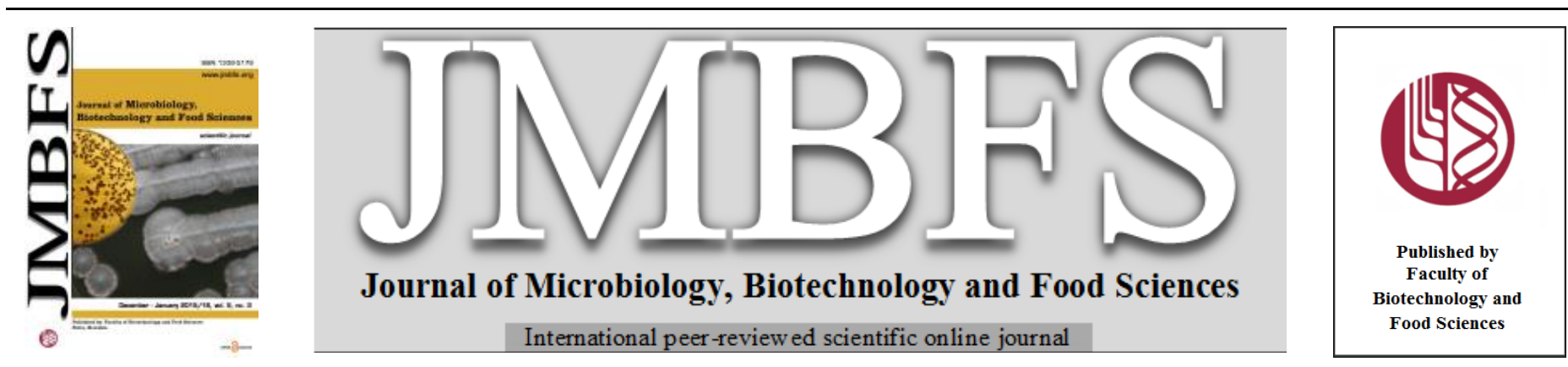

\title{
PURIFICATION AND STRUCTURAL CHARACTERIZATION OF A PHTHALATE ANTIBIOTIC FROM BURKHOLDERIA GLADIOLI OR1 EFFECTIVE AGAINST MULTI-DRUG RESISTANT STAPHYLOCOCCUS AUREUS
}

\author{
Pratibha Bharti ${ }^{1 *}$, Rupinder Tewari ${ }^{2}$ \\ Address(es): Dr. Pratibha Bharti, \\ ${ }^{1}$ Shaheed Udham Singh College of Research \& Technology, Department of Biotechnology, Tangori, 140306, Mohali, Punjab; +91-9872261100. \\ ${ }_{2}^{2}$ Panjab University, Centre for Microbial Biotechnology, 160014, Chandigarh.
}

*Corresponding author: bharti_pratibha@yahoo.com

doi: $10.15414 / j m b f s .2015 / 16.5 .3 .207-211$

\section{ARTICLE INFO}

Received 20. 5. 2015

Revised 29. 7. 2015

Accepted 31. 8. 2015

Published 1. 12. 2015

Regular article

OPEN $\partial_{\text {ACCESS }}$

\section{ABSTRACT}

A soil isolate, identified as Burkholderia gladioli OR1, has been reported in our earlier study, to possess broad spectrum antimicrobial activity against drug resistant clinical isolates of bacteria and fungi. The 16S rRNA gene sequence data of $B$. gladioli strain OR1 has been deposited in the GenBank databases (MTCC) under the accession number MTCC11251. Thin layer chromatography and bioautography studies of chloroform extract of the cell free supernatant of this organism, showed at least four different antimicrobial compounds. The silica gel column chromatography and high performance liquid chromatography led to the isolation of one compound that exhibited growth inhibitory activity against multi-antibiotic resistant clinical isolates of Staphylococcus aureus (resistant to amikacin, ciprofloxacin, clindamycin, clinafloxacin, erythromycin, gentamicin and methicillin). On the basis of mass, infra-red (IR), ${ }^{1} \mathrm{H}$ nuclear magnetic resonance (NMR), ${ }^{13} \mathrm{C}$ NMR and 2D NMR spectral studies, we propose the structure of this antibiotic to be bis-(2ethylhexyl) phthalate, isolated for the first time from the species of the genus Burkholderia.

Keywords: Antibiotic resistant, chloroform extract, chromatography, silica gel, spectroscopy

\section{INTRODUCTION}

The number and complexity of infections caused by microbial pathogens are continuously rising and have become a real problem today. To worsen the situation further, antimicrobial resistance among clinical microbial pathogens has been increasing steadily during the past several decades, leading to the isolation of multi-drug resistant pathogens from hospitals all over the world Staphylococcus aureus is one of the most important pathogens posing serious health hazard, because of its exceptional virulence, stress tolerance and high capacity to induce antimicrobial resistance (De Leo and Chambers, 2009).

In the absence of any effective vaccine against $S$. aureus, it is imperative that new antimicrobials are identified to combat infections mediated by drug-resistant $S$. aureus. Natural products derived from "microbes" have long been an inspiration for the development of drugs with applications in the field of human health (Stewart et al., 2004). In the incessant search for less toxic, more potent antibiotics responsive to the major pathogens which have acquired resistance to the existing antibiotics, a novel strain Burkholderia gladioli OR1, isolated from rhizospheric soil, was found to exhibit activity against multi-drug resistant (MDR) clinical pathogen, S. aureus. Based on the thin layer chromatography (TLC) and bio-autography studies, it produced two heat stable $\left(100^{\circ} \mathrm{C} / 20 \mathrm{~min}\right)$ (373.15 K/1200 s) and chloroform soluble antimicrobial compounds (Bharti et al., 2011). The objective of our study was the purification and characterization of atleast one of these active compounds.

\section{MATERIALS AND METHODS}

\section{Production and preparation of crude extract}

The nutrient medium and incubation conditions required for the growth of $B$ gladioli OR1, as well as the preparation of chloroform extract (possessing antistaphylococcal activity) from cell free culture supernatant have been mentioned in our earlier publication (Bharti et al., 2011). In brief, B. gladioli OR1 was cultivated in glucose yeast extract medium (glucose- $1.0 \% \mathrm{w} / \mathrm{v}$, yeast extract$0.05 \% \mathrm{w} / \mathrm{v} ; \mathrm{pH}-7.0)$ at $30^{\circ} \mathrm{C}$ for $24 \mathrm{~h}(303.15 \mathrm{~K}$ for $86400 \mathrm{~s})$ under shaking conditions. The culture was centrifuged (HITACHI, Japan) and the cell free supernatant was extracted with equal volume of chloroform. The organic fraction was separated and concentrated in a vacuum rotavapour $\left(35^{\circ} \mathrm{C} / 100 \mathrm{rpm}, \mathrm{BUCHI}\right.$, Switzerland) yielding brownish paste, which was tested for activity against clinical pathogens including MDR $S$. aureus (obtained from Department of Microbiology, Government Medical College and Hospital, Chandigarh, India).

\section{Purification of the antimicrobial compound}

Initial fractionation of the brownish paste containing antimicrobial compounds, was done using vacuum liquid chromatography (VLC), in which $22.0 \mathrm{~g}(0.022$ $\mathrm{kg}$ ) of the crude chloroform extract of B. gladioli OR1 was dry loaded gently over the silica gel G (CDH Fine-chem., India) bed made into a column of 10 inch diameter X 14 inch height $(0.254 \mathrm{~m}$ X $0.355 \mathrm{~m})$ in a G-4 sintered glass funnel. Elution was done under vacuum, using a step-wise gradient of solvents, starting with $100 \%$ hexane, then adding hexane-ethyl acetate increasing ethyl acetate up to $100 \%$ and finally giving a wash with methanol : ethyl acetate $(1: 1)$. A total of 50 fractions $\left(250 \mathrm{ml}\right.$ i.e., $0.0003 \mathrm{~m}^{3}$ each) were collected and pooled on the basis of TLC profiling to give sixteen major pools. The active fraction (exhibiting activity against MDR $S$. aureus) obtained from VLC using 5\% (v/v) methanol in ethyl acetate, exhibited minimum number of separable spots, as determined by TLC-bioautography and was chosen for further purification using flash column chromatography (FCC). In FCC, a column (dimensions $-18 \mathrm{~cm} \mathrm{X} 1.5 \mathrm{~cm}$ i.e., $0.18 \mathrm{~m} \mathrm{X} 0.015 \mathrm{~m})$ was packed with $12 \mathrm{~g}(0.012 \mathrm{~kg})$ activated (heating for $1 \mathrm{~h}$ at $110^{\circ} \mathrm{C}$ or $3600 \mathrm{~s}$ at $\left.383.15 \mathrm{~K}\right)$ silica gel (230-400 mesh size) and equilibrated using chloroform. The isocratic elution of the loaded active fraction was done using $\mathrm{CHCl}_{3}: \mathrm{CH}_{3} \mathrm{OH}$ (chloroform-methanol) :: $95: 5$ (v/v) yielding 65 fractions ( $25 \mathrm{ml}$ or $2.5 \times 10^{-5} \mathrm{~m}^{3}$ each), which were pooled into 5 major fractions based on the TLC analysis.

The fractions eluted from FCC, whose RP-TLC (reverse phase TLC- MERCK Co., USA) revealed one major spot were then subjected to analytical high performance liquid chromatography (HPLC) [SHIMADZU-SCL-10AVP (Japan), injection volume - $10 \mu \mathrm{l}$ of $1 \mathrm{mg} \mathrm{ml}^{-1}\left(1 \mu \mathrm{l}=10^{-9} \mathrm{~m}^{3}, 1 \mathrm{mg}=10^{-6} \mathrm{~kg}\right)$ sample, column - Phenomenex $\mathrm{C}_{18} 250 \mathrm{~mm} \mathrm{X} 4.6 \mathrm{~mm}(0.025 \mathrm{~m} \mathrm{X} 0.0046 \mathrm{~m})$, flow rate $-1 \mathrm{ml} \mathrm{min}{ }^{-1}$, detection wavelength $-252 \mathrm{~nm}$, elution gradient - 0-30 min $-50-100 \% \mathrm{v} / \mathrm{v}$ methanol in water $\}$. The fraction showing a few separable peaks in the max plot from analytical HPLC was further purified using semi preparative HPLC \{SHIMADZU-SCL-10AVP, injection volume - $100 \mu \mathrm{l}$ of $30 \mathrm{mg} \mathrm{ml}^{-1}$ filtered sample in the SIL-20AC auto-sampler, column - RP-Princeton $250 \mathrm{~mm} \mathrm{X}$ $20 \mathrm{~mm}(0.25 \mathrm{~m} \mathrm{X} 0.02 \mathrm{~m})$, flow rate $-3 \mathrm{ml} \mathrm{min}^{-1}$, solvent system $-58 \% \mathrm{v} / \mathrm{v}$ methanol (HPLC Grade- J.T. BAKER, USA) in water isocratic $\}$. 


\section{Antimicrobial assay of the isolated compound}

The pure compound obtained was checked for antagonistic activity using the same assays as done earlier for the crude extract i.e., disc-diffusion method and TLC-bioautography technique (Bharti et al., 2011) against clinical drug resistant $S$. aureus strains. In brief, for disc-diffusion assay, ten microlitres $\left(10^{-8} \mathrm{~m}^{3}\right)$ of the purified sample obtained from semi-preparative HPLC, was applied on each sterile filter paper discs (6 mm diameter, HI-MEDIA, India) $\left(0.05 \mathrm{mg} \mathrm{ml}^{-1}\right.$ of methanol i.e., $0.5 \mu \mathrm{g} / \mathrm{disc})$. The impregnated discs were air dried and placed on each nutrient agar plate, spreaded individually with 10 strains of antibiotic resistant $S$. aureus isolated from various sites of human patients (Tab 1). For bioautography assay, $20 \mu \mathrm{l}\left(2 \times 10^{-8} \mathrm{~m}^{3}\right)$ of this pure compound was applied on silica gel 60 TLC strip (F 254, MERCK Co, USA), developed in $\mathrm{CHCl}_{3}: \mathrm{CH}_{3} \mathrm{OH}$ :: $9: 1$ (v/v), air-dried and examined under ultra violet (UV) light $(254 \mathrm{~nm} \& 366$ $\mathrm{nm}$ ). This TLC strip was then placed on a media plate which was then overlaid with soft nutrient agar (agar- $1.0 \%$ w/v) containing actively growing MDR $S$. aureus. The plates for both the assays were incubated at $30^{\circ} \mathrm{C}$ for $24 \mathrm{~h}$ and the zone diameters and $\mathrm{R}_{\mathrm{f}}$ value calculated respectively.

\section{Structural characterization of the purified antimicrobial compound}

Once pure active compound was isolated, its identity was determined by spectroscopic methods including mass, IR and NMR spectral studies. The molecular mass of the isolated compound was ascertained by MS instrument (WATERS Q-ToF Micro, USA) in a suitable solvent (methanol) over a range of $0-1000 \mathrm{~m} / \mathrm{z}$ in API-ES-MS, by injecting at a continuous flow of $5 \mu \mathrm{min}^{-1}$ with set ionization parameters (capillary dissolvation voltage and temperature: $3000 \mathrm{~V}$ $\& 200^{\circ} \mathrm{C}$ ). IR spectrum of the compound was taken in solubilized form on a $\mathrm{KBr}$ window to get an idea about the various functional groups present, using FT-IR (fourier transform IR-PERKIN ELMER, USA). The active pure compound was then submitted for ${ }^{1} \mathrm{H}(400 \mathrm{MHz}),{ }^{13} \mathrm{C}(100 \mathrm{MHz})$ and 2-Dimensional NMR spectral studies including distortionless enhancement by polarization transfer spectroscopy (DEPT), ${ }^{1} \mathrm{H}-{ }^{1} \mathrm{H}$ homonuclear correlated spectroscopy $\left({ }^{1} \mathrm{H}-{ }^{1} \mathrm{H}-\right.$ COSY), ${ }^{1} \mathrm{H}-{ }^{13} \mathrm{C}$ heteronuclear multiple bond coherence spectroscopy $\left({ }^{1} \mathrm{H}-{ }^{13} \mathrm{C}\right.$ $\mathrm{HMBC})$ and ${ }^{1} \mathrm{H}-{ }^{13} \mathrm{C}$ heteronuclear multiple quantum coherence spectroscopy $\left({ }^{1} \mathrm{H}-\right.$ ${ }^{13} \mathrm{C}$-HMQC) (AVANCE III 400 BRUCKER, Switzerland) using TMS (tetra methyl-silane) as the internal standard.

\section{RESULTS}

The cell free culture supernatant of $B$. gladioli OR1 was extracted with chloroform, which was then concentrated to yield a solid brownish mass (yield$200 \mathrm{mg}$ per litre). This dry residue was stored at $-20^{\circ} \mathrm{C}$ for further use.

\section{Fractionation of the crude extract}

Out of the 16 major fractions obtained from VLC of the chloroform extract of $B$ gladioli OR1, fractions $7^{\text {th }}$ to $16^{\text {th }}$, eluted using comparatively polar solvent $(50 \%$ - $100 \% \mathrm{v} / \mathrm{v}$ ethyl-acetate in hexane and upto $50 \% \mathrm{v} / \mathrm{v}$ methanol in ethyl acetate) were found to be active and exhibited at least a single zone against MDR $S$. aureus upon bioautography. Out of these, fraction $12^{\text {th }}(200 \mathrm{mg})$ exhibited separable spots on TLC (under UV light), and hence was further chosen for purification using FCC. Out of the 5 major fractions of $12^{\text {th }}$ i.e., $12-1-\mathrm{F}$ to $12-5-\mathrm{F}$, 12-2-F exhibited single major spot on RP-TLC.

\section{Isolation of pure antimicrobial compound}

Analytical HPLC of 12-2-F (30 mg or $3 \times 10^{-5} \mathrm{~kg}$ ) exhibited 4 major peaks at different retention times methanol-water $\left(\mathrm{CH}_{3} \mathrm{OH}-\mathrm{H}_{2} \mathrm{O}\right)$ gradient. Using semipreparative HPLC, a total of 5 peaks of $12-2-\mathrm{F}$ were thus collected (12-2F-1 to $12-2 \mathrm{~F}-5)$ at various retention times using a solvent mixture $\mathrm{CH}_{3} \mathrm{OH}-\mathrm{H}_{2} \mathrm{O}$.

Profiling of the light brown fraction 12-2F-4 (4 mg) using analytical HPLC revealed a single peak in the chromatogram thus confirming its purity (Fig. 1).

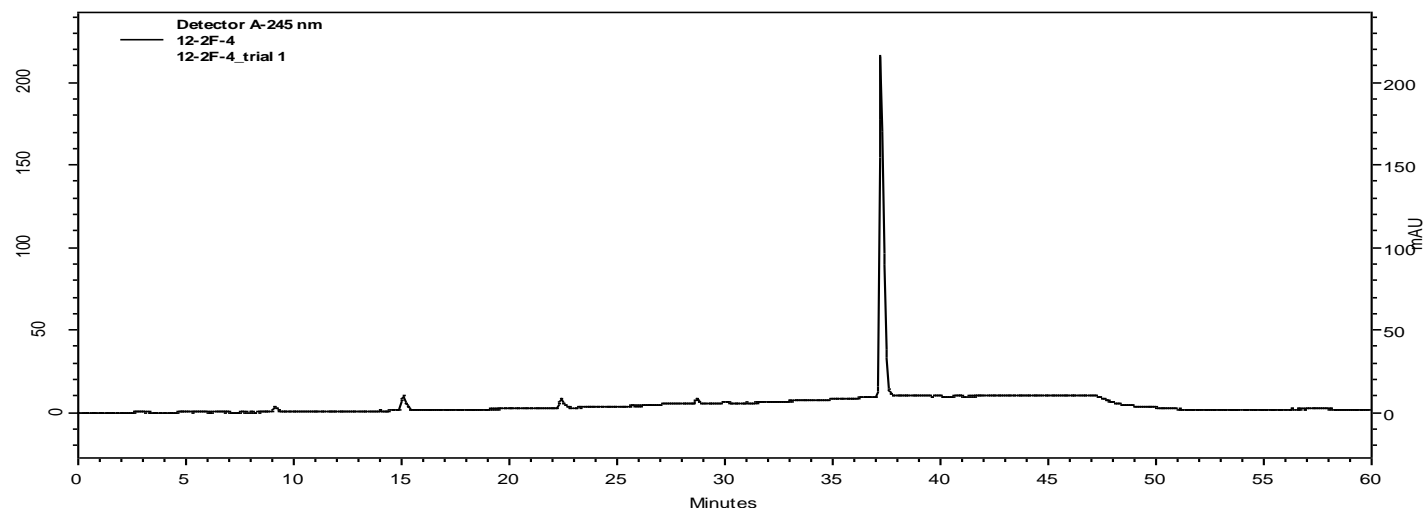

Figure 1 Analytical HPLC chromatogram depicting single peak in 12-2F-4 fraction purified from the extract of Burkholderia gladioli OR1.

\section{Anti- Staphylococcus aureus activity of the pure compound}

The pure compound 12-2F-4 obtained, was found to exhibit appreciable anti-S aureus zone of inhibition (13.5-14 mm i.e., 0.0135-0.014 m diameter) (Fig. 2) against a number of antibiotic resistant clinical strains (Tab 1).
Three major anti-S. aureus bands were obtained (Fig. 3A). 12-2F-4 exhibited a single TLC band when visualized under UV light $(254 \mathrm{~nm})$ (Fig. 3B), further emphasizing its pure nature. This band at $R_{f}$ value of 0.45 was one of the major bands present in the crude extract of $B$. gladioli OR1 (Fig. 4A \& 4B).

Table 1 Activity spectrum of the pure compound from B. gladioli OR1 against various drug resistant clinical isolates of S. aureus.

\begin{tabular}{llcc}
\hline S. No. & Test strain (Source) & $\begin{array}{c}\text { No. of } \\
\text { strains }\end{array}$ & Resistance to drug/s \\
\hline 1. & Staphylococcus aureus (Umbilical tip)* & 1 & AMK, CIP, CLI, CLX, ERY, GEN, MET \\
\hline 2. & S. aureus (Pus/Semen) & 2 & ERY, GEN \\
\hline 3. & S. aureus (Wound) & 1 & GEN \\
\hline 4. & S. aureus (Pus/Wound) & 3 & CLX \\
\hline 5. & S. aureus (Wound) & 2 & AMK, CIP, ERY, GEN \\
\hline 6. & S. aureus (Tissue cells) & 1 & AMK, CLX, GEN \\
\hline
\end{tabular}

Note: * Strain selected for experimental observations.

The control sterile filter paper disc, loaded with $10 \mu \mathrm{l}$ of methanol and air dried at room temperature, did not exhibit any antimicrobial activity. AMK - Amikacin, CIP - Ciprofloxacin, CLI - Clindamycin, CLX - Clinafloxacin, ERY - Erythromycin, GEN - Gentamicin, MET - Methicillin. 


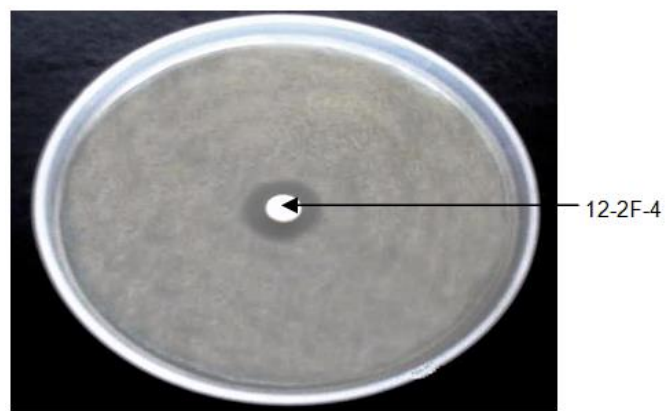

Figure 2 Zone of inhibition exhibited by the isolated pure compound 12-2F-4 against multi drug resistant Staphylococcus aureus.



(A)

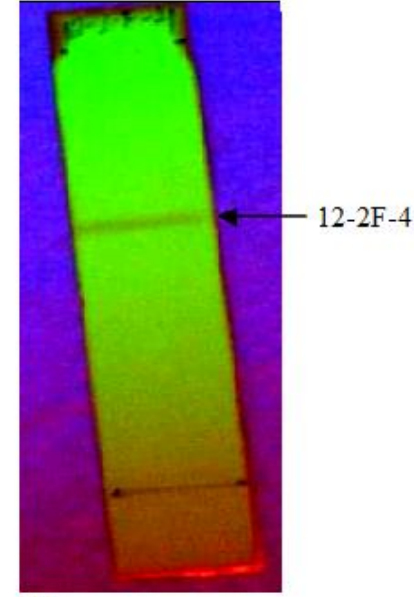

(B)
Figure 3 Comparative localization of bands on TLC (under UV light) in the (A) crude extract; (B) isolated spot 12-2F-4 obtained from B. gladioli OR1.

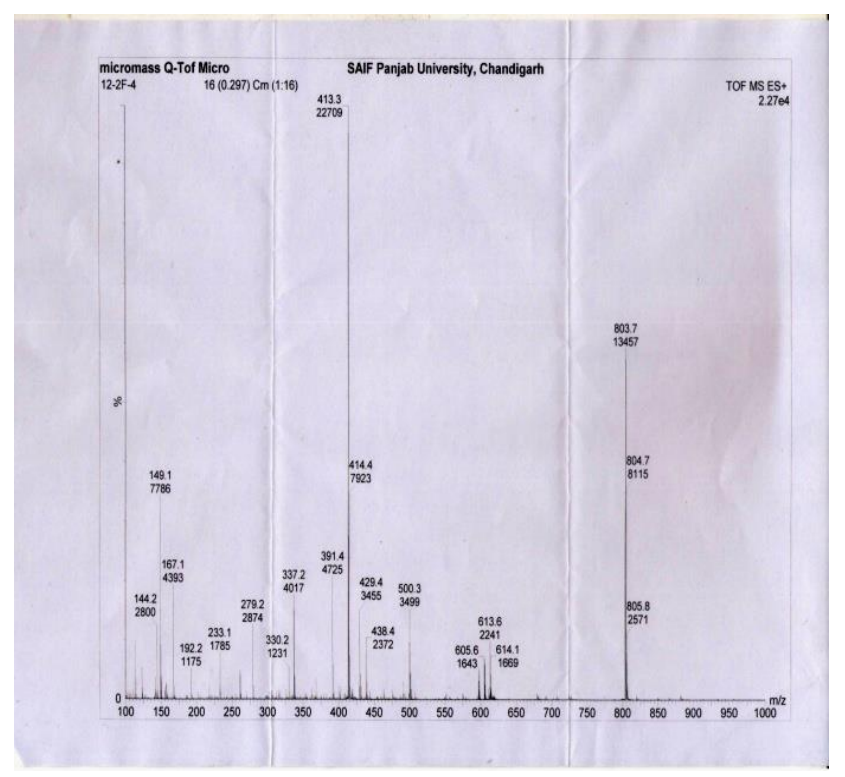

(A)

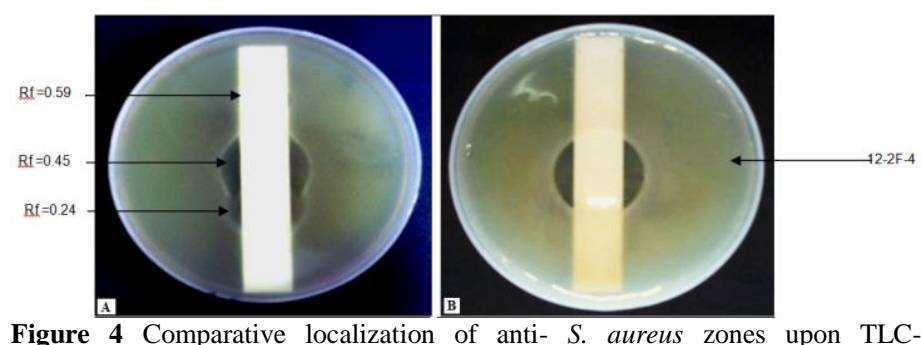

bioautography analysis in the (A) crude extract; (B) isolated spot 12-2F-4.

\section{Structural characterization of the pure active compound}

The positive mode APCI mass spectrum of $12-2 \mathrm{~F}-4$, showed $[\mathrm{M}+1]^{+}$molecular ion peak at $\mathrm{m} / z, 391.4$ suggesting that the molecular weight of the compound was 390 (Fig. 5A). IR spectrum of 12-2F-4 showed bands at 3430, 2919, 1633 and 1260, which indicated the presence of $\mathrm{NH}(\mathrm{OH}), \mathrm{CH}, \mathrm{C}=\mathrm{C}$ and $\mathrm{C}-\mathrm{O}$ groups respectively (Fig. 5B).

The ${ }^{1} \mathrm{H}$ NMR spectrum of $12-2 \mathrm{~F}-4$ showed signals for two aromatic protons at $\delta$ $7.50(2 \mathrm{H}, \mathrm{d}, J=2.8 \mathrm{~Hz})$ and $7.41(2 \mathrm{H}, \mathrm{d}, J=3 \mathrm{~Hz})$. The spectrum also exhibited the presence of 10 methylene protons, 8 of which showed overlapping signals in the range $\delta 1.24-0.92\left(8 \mathrm{H}, 4 \mathrm{XCH}_{2}\right)$, and the remaining two protons at $3.99(2 \mathrm{H}$, $1 \mathrm{XCH}_{2}$ ). The signals for four methyl groups were in the range 0.74-0.69. A multiplet for one methine proton appeared at $\delta 1.46$ (Fig. 5C).

The ${ }^{13} \mathrm{C}$ NMR and DEPT spectral analysis of $12-2 \mathrm{~F}-4$ indicated 12 carbons at $\delta_{\mathrm{C}}$ 169.4, 133.6, 132.4 129.9, 69.1, 40.2, 31.6, 30.1, 25.0, 24.0, 14.4 and 11.4. These were 4 terminal methyls (14.4 and 11.4), 2 aromatic carbons (132.4 and 129.9), 4 methylenes $\left(31.6,30.1,25.0\right.$ and 24.0), $1 \mathrm{OCH}_{2}$ (69.1), 1 methine (40.2) and 2 quaternary carbons (169.4 and 133.6) (Fig. 5D).

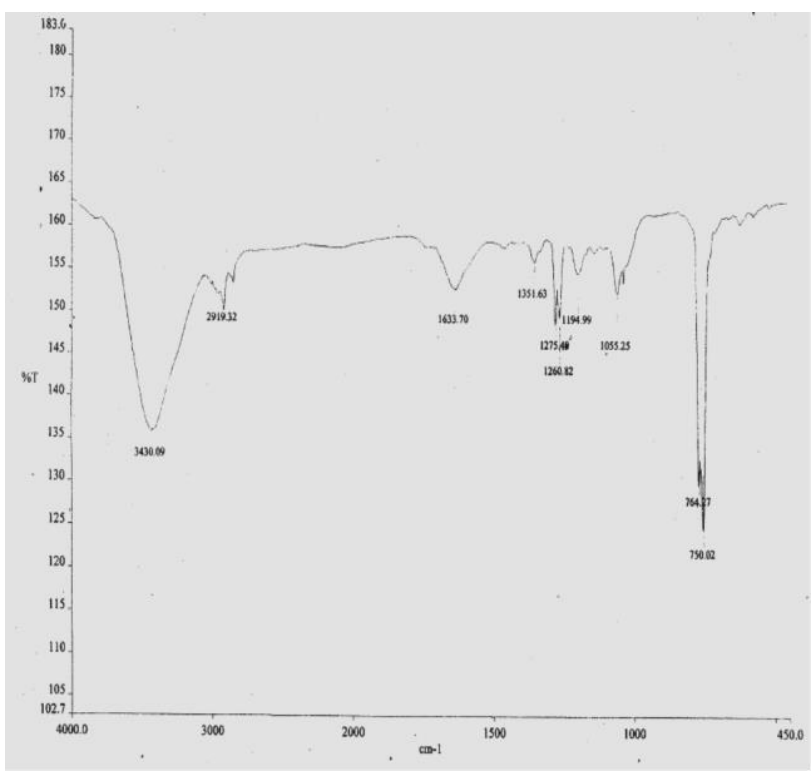

(B) 

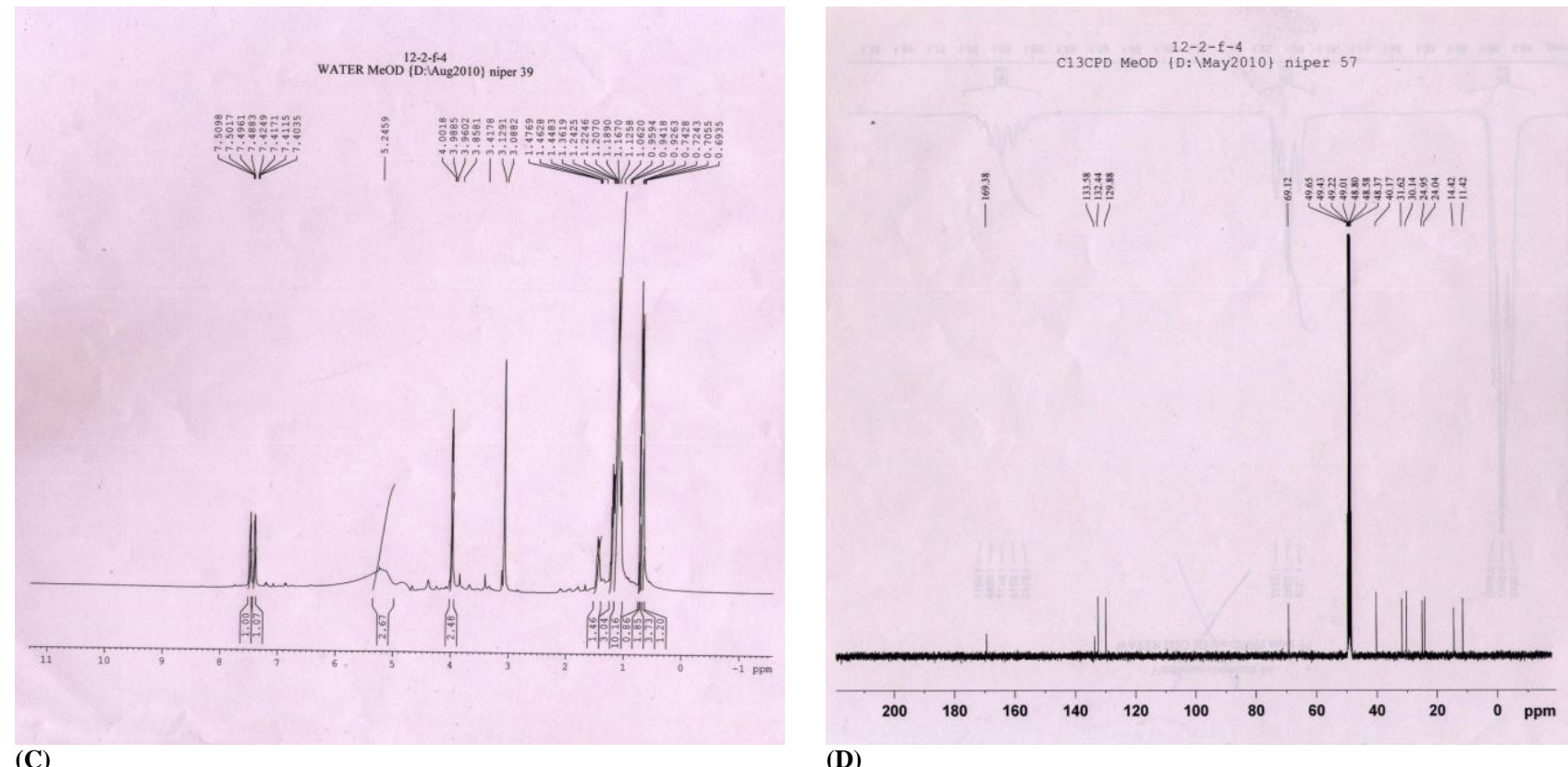

Figure 5 Spectroscopic data including (A) mass spectrum, (B) infra red spectrum, (C) ${ }^{1} \mathrm{H}$ nuclear magnetic resonance spectrum and (D) ${ }^{13} \mathrm{C}$ NMR spectrum of the pure active compound $12-2 \mathrm{~F}-4$.

The simplicity and clarity of the ${ }^{1} \mathrm{H}$ NMR and ${ }^{13} \mathrm{C}$ NMR spectra for $12-2 \mathrm{~F}-4$, led us to study its detailed structure using 2-D (dimensional) NMR $\left\{{ }^{1} \mathrm{H}^{-1} \mathrm{H}\right.$ COSY $\mathrm{HMQC}, \mathrm{HMBC}\}$ spectroscopy. The ${ }^{1} \mathrm{H}-{ }^{-1} \mathrm{H}-\mathrm{COSY}$ spectrum of $12-2 \mathrm{~F}-4$ showed correlation between protons positioned at $\delta_{\mathrm{H}} 3.99$ and 1.46. The structure of the alkyl chain and substitution pattern at aromatic ring was confirmed by

determining connectivity of $\mathrm{C}$ atoms from ${ }^{1} \mathrm{H}^{1}{ }^{13} \mathrm{C}-\mathrm{HMBC}$ spectrum; substitution pattern of benzene ring as confirmed by the ${ }^{1} \mathrm{H}^{13}{ }^{13} \mathrm{C}-\mathrm{HMBC}$ correlations and ${ }^{1} \mathrm{H}$ NMR splitting pattern led to fragment $\mathbf{A},{ }^{1} \mathrm{H}^{13}{ }^{13} \mathrm{C}$ - $\mathrm{HMBC}$ correlations of protons at $\delta_{\mathrm{H}} 3.99$ and 1.46 with $2 \mathrm{CH}_{2}$ carbons indicated fragment $\mathbf{B}$ while ${ }^{1} \mathrm{H}-{ }^{13} \mathrm{C}-\mathrm{HMBC}$ correlations and ${ }^{1} \mathrm{H}-{ }^{1} \mathrm{H}-\mathrm{COSY}$ of terminal methyl groups present in the side chain confirmed the presence of 2 subunits B and $\mathbf{C}$ (Fig. 6).

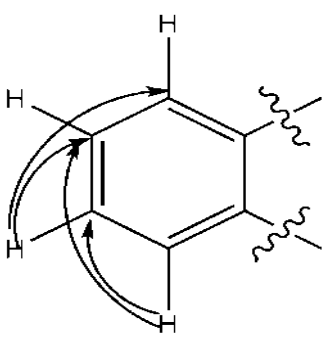

Fragment A

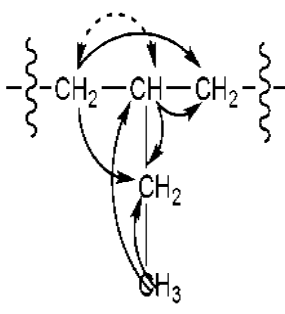

Fragment B
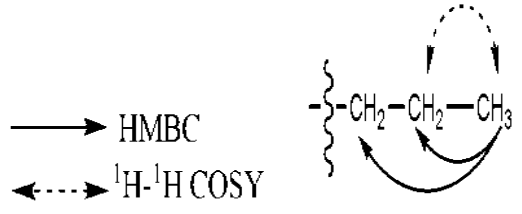

Fragment $C$

Figure 6 Major subunits of the pure active compound 12-2F-4 as elucidated by the spectral analysis.

The NMR data exhibiting the carbon resonances confirmed the symmetry of the molecule with formula $\mathrm{C}_{6} \mathrm{H}_{4}\left(\mathrm{C}_{8} \mathrm{H}_{17} \mathrm{COO}\right)_{2}$. The final interpretation of all the combined spectral data suggested that the isolated pure compound from $B$ gladioli OR1 with anti-S. aureus activity is a symmetrical phthalate ester identified as bis-(2-ethylhexyl) phthalate (Fig. 7).


Figure 7 Chemical structure of the anti- S. aureus compound \{bis-(2-ethylhexyl) phthalate\}, purified from B. gladioli OR1.

\section{DISCUSSION}

In our earlier study, the chloroform extract containing antimicrobial compounds was found to inhibit the growth of many strains of antibiotic-resistant $S$. aureus (zone size: $15.0-33.0 \mathrm{~mm}$ or $0.015-0.033 \mathrm{~m}$ ). The active extract revealed many bands in TLC analysis under UV light ( $254 \mathrm{~nm}$ and $366 \mathrm{~nm}$ ) with $\mathrm{R}_{\mathrm{f}}$ values 0.24 $0.45,0.59,0.62$ and 0.76 , and with three of them (corresponding to $R_{f}$ values 0.24, 0.45 and 0.59) possessing anti-S. aureus activity (Bharti et al., 2011). This led us to undertake the process of purification and characterization of active compounds possessing activity against MDR S. aureus. However, the compound responsible for biological activity is often present in trace amounts against a background of large amounts of biosynthetically related and structurally unrelated metabolites making the process challenging. The versatility, resolving capability, and quantitative accuracy of HPLC makes it one of the best direct methods to study the production of antibiotics in situ (Raaijmakers et al., 2002). This is among a few reports on the complete characterization of an antimicrobial compound from $B$. gladioli. Only in the recent past, a single study has reported 
the isolation of two bioactive volatile compounds, a liquid hydrocarbon cyclic terpene and a flavonone, with antifungal activity from Burkholderia gladioli pv. agaricicola (Elshafie et al., 2013). Earlier, Box et al. (1988) and Gwynn et al. (1988) reported the partial characterization of antimicrobial compounds belonging to the members of monobactam and bulgecin family of antibiotics from B. gladioli.

Moreover, this is the first report on the production of bis-(2-ethylhexyl) phthalate by any unicellular bacteria such as those belonging to the genus Burkholderia. This compound has been earlier isolated primarily from filamentous bacteria like Nocardia levis (Kavitha et al., 2009), Streptomyces bangladeshiensis (Al-Bari et al., 2006), Streptomyces avidinii (Lyutskanova et al., 2009), Streptomyces sp. TN17 (Smaoui et al., 2011), Streptomyces mirabilis NSQu-25 (El-Sayed, 2012) and other actinomycetes like Saccharothrix sp. (Johnson et al., 2012).

\section{CONCLUSION}

The incessant search for less toxic, more potent antibiotics, which are effective against the drug-resistant strains of major and opportunistic pathogens, led us to isolate and purify a pure compound from B. gladioli OR1. This compound identified as bis-(2-ethylhexyl) phthalate was found to exhibit potential activity against multi antibiotic resistant nosocomial pathogen $S$. aureus. B. gladioli can thus be looked upon as a potential source for the production of a novel class of antibiotics, effective against pathogens, resistant to the previously available antiinfective drugs. Further, chemical modification of purified anti-staphylococcal compound may be undertaken to enhance its antimicrobial activity.

Acknowledgement: The authors are grateful to the Department of Microbiology, Government Medical College and Hospital, Sector-32, Chandigarh for providing drug resistant clinical microbial strains.

\section{REFERENCES}

AL-BARI, M.A.A., SAYEED, M.A., RAHMAN, M.S., MOSSADIK, M.A. 2006. Characterization and antimicrobial activities of a phthalic acid derivative produced by Streptomyces bangladeshiensis a novel species collected in Bangladesh. Res. J. Med. Med. Sci., 1, 77-81.

BHARTI, P., ANAND, V., CHANDER, J., SINGH, I.P., SINGH, T.V., TEWARI, R. 2012. Heat stable antimicrobial activity of Burkholderia gladioli OR1 against clinical drug resistant isolates. Ind. J. Med. Res., 135(5), 666-671.

BOX, S.J., BROWN, A.G., GILPIN, M.L., GWYNN, M.N., SPEAR, S.R. 1988 MM 42842, a new member of the monobactam family produced by Pseudomonas cocovenenans II: Production, isolation and properties of MM 42842. J. Antibiot., 41, 7-12. http://dx.doi.org/10.7164/antibiotics.41.7

DELEO, F.R., CHAMBERS, H.F. 2009. Reemergence of antibiotic-resistan Staphylococcus aureus in the genomics era. J. Clin. Invest., 119, 2464-2474. http://dx.doi.org/10.1172/JCI38226

EL-SAYED, M.H. 2012. Di-(2-ethylhexyl) phthalate, a major bioactive metabolite with antimicrobial and cytotoxic activity isolated from the culture filtrate of newly isolated soil Streptomyces (Streptomyces mirabilis strain NSQu25). World Appl. Sci. J., 20(9), 1202-1212.

ELSHAFIE, H. S., BUFO, S. A., RACIOPPI, R., CAMELE, I. 2013 Biochemical characterization of volatile secondary metabolites produced by Burkholderia gladioli pv. agaricicola. Int. J. Drug Discov., 5(1), 181. http://dx.doi.org/10.9735/0975-4423.5.1.181-184

GWYNN, M.N., BOX, S.J., BROWN, A.G., GILPIN, M.L. 1988. MM 42842, a new member of the monobactam family produced by Pseudomonas cocovenenans. I: Identification of the producing organism. J. Antibiot., 41, 1-6. http://dx.doi.org/10.7164/antibiotics.41.1

JOHNSON, J. A., CITARASU, T., MARY HELEN, P. A. 2012. Screening of antibiotic producing Actinomycetes from streams. J. Chem. Biol. \& Phy. Sci., 2(3), 1363-1370.

KAVITHA, PRABHAKAR, P., VIJAYALAKSHMI, M., VENKATESWARLU, Y. 2009. Production of bioactive metabolites by Nocardia levis MKVL_113. Lett. Appl. Microbiol., 49, 484-490. http://dx.doi.org/10.1111/j.1472765X.2009.02697.X

LYUTSKANOVA, D., IVANOVA, V., STOILOVA-DISHEVA, M. KOLAROVA, M., ALEKSIEVA, K., PELTEKOVA, V. 2009. Isolation and characterization of a psychrotolerant Streptomyces strain from permafrost soil in Spitsbergen, producing phthalic acid ester. Biotechnol. \& Biotechnol. Equip., 23, 1220-1224. http://dx.doi.org/10.1080/13102818.2009.10817642

RAAIJMAKERS, J.M., VLAMI, M., DE SOUZA, J.T. 2002. Antibiotic production by bacterial biocontrol agents. Anton. Van Leeuw., 81(1-4), 537-547. http://dx.doi.org/10.1023/A:1020501420831

SMAOUI, S., MELLOULI, L., LEBRIHI, A., COPPEL. Y., FOURATI, L., FGUIRA, B., MATHIEU, F. 2011. Purification and structure elucidation of three naturally bioactive molecules from the new terrestrial Streptomyces sp. TN17 strain. Nat. Prod. Res., 25, 806-814. http://dx.doi.org/10.1080/14786410902986225

STEWART, M., CAPON, R.J., WHITE, J.M., LACEY, E., TENNANT, S. GILL, J.H., SHADDOCK, M.P. 2004. Rugulotrosins A and B: Two new antibacterial metabolites from an Australian isolate of a Penicillium sp. J. Nat. Prod., 67, 728-7 